\title{
ANÁLISE COMPARATIVA E HISTÓRICA DA CONCEPÇÃO URBANÍSTICA DE ATTILIO CORRÊA LIMA E A ESTRUTURAÇÃO DO SETOR CENTRAL E DO SETOR SUL EM GOIÂNIA, GOIÁS
}

\section{Bruna Rodrigues Guimarães}

Pontifícia Universidade Católica de Goiás

Goiânia, Goiás - Brasil

bruna.guimaraes10@hotmail.com

\section{Antônio Pasqualetto}

Pontifícia Universidade Católica de Goiás

Goiânia, Goiás - Brasil

profpasqualetto@gmail.com

\section{Júlia Pereira de Sousa Cunha}

Pontifícia Universidade Católica de Goiás

Goiânia, Goiás - Brasil

juliaps11@hotmail.com

Recebido em 30/09/2020. Aprovado em 09/1 1/2020.

DOI: dx.doi.org/10.5380/guaju.v6i2.76771

\section{Resumo}

Objetivou-se realizar um levantamento histórico e de dados dos bairros Central e Sul, localizados na cidade de Goiânia - GO, com a finalidade de mostrar as alterações que ocorreram nos últimos 86 anos desde a concepção de seu projeto urbanístico por Attilio Corrêa Lima. Foi elaborado um estudo do espaço a fim de compreender as formas de ocupação, a realidade social, as características dos bairros, o estímulo de crescimento, o perfil da população residente, os marcos históricos e a infraestrutura. O intuito do trabalho é compreender e analisar a evolução que ambos os bairros sofreram nesse período.

Palavras- chave: Alteração. Crescimento. Planejamento. 


\title{
Comparative and historical analysis of the urban design of Attilio Corrêa Lima and the structuring of the Central and the South neighborhood in Goiânia, Goiás
}

\begin{abstract}
The present work has the objective of making a historical and data collection of the central and southern districts, located in the city of Goiania - GO, with the purpose of showing the changes that were made in the last eighty six years. In the text was elaborated a study to understand the forms of occupancy, the characteristics of the neighborhood, the social reality, the growth, the profile of the resident population and the historical milestones. The purpose of the work is to understand and analyze the evolution that both disctricts suffered in this period.
\end{abstract}

Keywords: Modification. Development. Planning. 


\section{Introdução}

A cidade de Goiânia foi fundada no ano de 1933 no intuito de ser intitulada capital do estado de Goiás, substituindo a então Cidade de Goiás. O interventor Pedro Ludovico Teixeira acreditava ser necessária essa mudança de capital como uma forma de justificar a presença da Revolução de 1930 e trazer a modernidade para o estado.

O projeto urbanístico começou a ser idealizado por Attilio Corrêa Lima em 1932 após encomenda por Pedro Ludovico Teixeira. Attilio teve sua formação em arquitetura pela Escola Nacional de Belas Artes (ENBA) e quando assumiu o projeto da cidade planejada, era recém-formado em urbanismo no Institut d'Urbanisme de I'Université de Paris (IUUP). $\mathrm{O}$ traçado de Goiânia assume vários elementos que são característicos da formação de Corrêa Lima (VIEIRA, 2012, p. 54.)

O partido do projeto de Goiânia tem origem em sua topografia e dela nasceu a concepção do centro administrativo. Esse Centro Cívico ou Administrativo foi projetado para apresentar um efeito monumental, algo que fosse visto de outros pontos da cidade. As avenidas principais da cidade, chamadas de Araguaia, Pedro Ludovico e Tocantins, convergem nesse centro. Além de sua criação, Corrêa Lima organizou a cidade em cinco zonas: Administrativa, Comercial, Industrial e Residencial urbana e suburbana (MONTEIRO, 1938, p. 140.)

Em abril de 1935, Attilio rompe seu contrato com o estado de Goiás e os Irmãos Coimbra Bueno assumem o Plano Diretor, fazendo modificações no projeto de Goiânia. Uma das maiores alterações que foram efetuadas no plano original foi a executada no Setor Sul da capital, onde foi implantado um bairro-jardim (MOTA, 2016, p. 2).

O projeto da capital, apesar de ter sido fragmentado, foi inovador para uma região onde não havia tantos investimentos. A capital do estado de Goiás foi, portanto, prevista para cinquenta mil habitantes quando projetada (BARREIRA; DEUS, 2006, p. 75). Segundo o Censo do IBGE realizado em 2010, Goiânia possuia mais de um milhão de habitantes e é parte da Região Metropolitana de Goiânia. A cidade passou e passa por diversas transformações referentes não só ao crescimento populacional e de sua extensão, como também quanto a sua infraestrutura, perfil socioeconômico, características dos bairros ali presentes, entre outras.

O Plano da cidade de Goiânia parte da concepção tanto de Attilio Corrêa Lima 
quanto dos Irmãos Coimbra Bueno. Apesar das alterações ao longo do plano e de sua construção, o projeto de Goiânia inspirou o projeto da cidade de Palmas, com a estrutura viária e a organização espacial com a presença de um centro administrativo (DEL RIO; SIMBIEDA, 2013, p. 59).

O Setor Central é onde o projeto de Corrêa Lima passou por algumas modificações, mas ainda há a presença de seu traçado e do que inicialmente foi zoneado. O Setor Sul assume modificação drástica de projeto de Attilio desde 1935 com os Irmãos Coimbra Bueno. É um setor que ao longo dos anos foi modificando o que foi proposto no novo projeto e que teve um aumento no setor de serviços e comércio, descaracterizando o setor somente residencial proposto por Attilio.

Nesse sentido, busca-se compreender as transformações na cidade de Goiânia, com recorte dos bairros Setor Central e Setor Sul. Realizou-se análise dos bairros desde a sua concepção projetual, além de outros aspectos, como a população residente, o perfil socioeconômico, a infraestrutura, entre outros.

Este estudo foi realizado a partir de dados como mapas, tabelas e fotografias coletados e elaborados com o fito de apresentar o comparativo do que foi proposto no projeto original da capital nos setores anteriormente citados e como é a configuração destes na década de 2010.

\section{A construção da nova capital}

Pode-se inferir da criação da cidade de Goiânia que ela é parte de uma aliança política a fim de não só trazer o crescimento e o progresso ao Centro-Oeste do país, como também para beneficiar politicamente o interventor, Pedro Ludovico, e o então Presidente do país, Getúlio Vargas.

[...] Goiânia foi produto de uma demanda estadual enfrentada por Pedro Ludovico: sua idealização, construção e consolidação passam pela Revolução de 1930, entram no Estado Novo e ecoam na Marcha para o Oeste. (SILVA; MELLO, 2013, p. 61).

Sendo assim, segundo Morais (2003), Goiânia "surgiu como espécie de ponta-delança para a interiorização e modernização de parte do país rural: era a concretização do 
plano econômico da Marcha para o Oeste, anunciada pela política do Movimento de Trinta".

Asssinado em 18 de maio de 1933, o Decreto n. 3.359 delimitava as bases para a implantação da cidade de Goiânia, que em 1937 se tornaria a nova capital do estado de Goiás. A Cidade de Goiás passa a não ser mais capital do estado e Goiânia é tida como promessa de modernidade (CHAUL, 2009, p. 102).

[...] A mudança da capital passava ao seu significado mais global: um símbolo de ascensão ao poder, uma representação do progresso, do moderno, um divisor de águas entre o velho e o novo Goiás. (CHAUL, 2009, p. 103).

A nova capital assumiu esse posto de cidade moderna por ter sido implantada em "novos tempos" e, assim, sendo completamente diferente da chamada ultrapassada e antiga Cidade de Goiás. Naquela época, diversas áreas urbanas ao longo do país, como o Rio de Janeiro, São Paulo e Recife, passaram por mudanças com referências urbanísticas europeias e norte-americanas, banindo as referências coloniais e imperiais. Goiânia também é parte desse processo de progresso nacional como uma nova capital planejada por um arquiteto que recentemente havia retornado de Paris, França (SEGAWA, 2002, p. 26).

Attilio Corrêa Lima, arquiteto projetista de Goiânia, havia se formado na IUUP. Durante o tempo de estudo que passou em Paris, participou de um Congresso Internacional de Urbanismo, onde foi discutido cidades divididas em zonas especializadas. Participou como ouvinte do Congresso Internacional de Arquitetura Moderna (CIAM) e trabalhou no ateliê do urbanista Alfred Agache, responsável pelo plano de remodelação do Rio de Janeiro (DINIZ, 2007, p. 47). Sendo assim:

Corrêa Lima admirava a arquitetura colonial brasileira, porém, após o contato com as ideias inovadoras de Le Corbusier e os preceitos da arquitetura modernista, seus projetos começam a ter influências da nova arquitetura. (DINIZ, 2007, p. 47).

Os preceitos modernistas são visíveis na organização a partir de um zoneamento proposto para Goiânia. Mas o urbanista também foi influenciado pelo modelo formal e pelos paradigmas advindos da escola francesa de urbanismo. Pontos do projeto da cidade, como a presença do monumentalismo presente nos edifícios públicos do Centro Cívico e as largas avenidas convergindo para este centro, apresentam essa influência (DINIZ, 2007, p. 134). 


\section{O projeto do Setor Central e Setor Sul}

O Setor Central manteve o projeto original de Attilio Corrêa Lima. A concepção é caracterizada "pela regularidade e classicismo do traçado, determinado segundo as questões funcionais da circulação e as estéticas, visando dotar a nova capital de beleza monumental" (MOTA, 2016, p. 2).

O que é colocado como monumental no projeto de Goiânia é a presença do Centro Administrativo, que representa o órgão mais importante da cidade. Este

[...] é visto de todos os pontos da cidade e principalmente por quem nela chega. As três avenidas mais importantes convergem para o centro administrativo, acentuando a importância deste em relação à cidade, que na verdade deve-Ihe a sua existência. Guardando as devidas proporções, o efeito monumental procurado é o do princípio clássico adotado em Versailles, Karlsruhe e Washington. (MONTEIRO, 1938, p. 140).

Como a cidade fora zoneada em cinco partes, o Setor Central foi projetado em três zonas criadas pelo urbanista para o controle da cidade. Ele se encontra tanto na Zona Administrativa quanto na Zona Comercial e na Zona Residencial (VIEIRA, 2012, p. 58). A Zona Administrativa está localizada em torno do Centro Cívico, que fora detalhado assim:

[...] serão construídos todos os edifícios público administrativos, quer federais, estaduais ou municipais, salvo aqueles que por suas condições particulares exijam outra localização, como por exemplo, o edifício dos Correios e Telégrafos que, de preferência, deve ser acessível ao grande público, e que, por conseguinte, deverá estar na parte central da cidade. (MONTEIRO, 1938, p. 141).

O Centro Cívico ou Administrativo se torna, então, o ponto mais importante da cidade, onde não teria muito tráfego e seria de fácil acesso. Seu ingresso se daria a partir das Avenidas Tocantins, Pedro Ludovico, Araguaia e Ruas 10, 11, 26, 34 e 35 (MONTEIRO, 1938, p. 140).

A Zona Comercial foi inserida ao longo das Avenidas Pedro Ludovico, Araguaia e Tocantins. Já a Zona Residencial foi estabelecida urbana na área leste e oeste da cidade e suburbana, na área sul e Zona Rural (DINIZ, 2007, p. 134).

Sobre a Zona Comercial e sua inserção nas vias principais da cidade, Monteiro (1938, p. 141) expõe que: 
[...] A área mais central da cidade, onde gravita o comércio, onde a construção é mais densa. Esta zona, onde a circulação é mais intensa, possui uma rede de ruas e avenidas com largura suficiente para satisfazer ao tráfego por várias décadas, e com a possibilidade de alargamento das áreas de tráfego sem desapropriação.

Com o rompimento de Attilio no projeto da cidade, houve diversas modificações no projeto original. Quando os Irmãos Coimbra Bueno assumem o projeto, fazem diversas alterações com o intuito econômico. O projeto acaba sendo modificado por pressões políticas e econômicas e não por um desacordo sobre a concepção urbanística de Attilio, formando, assim, uma cidade fragmentada (DINIZ, 2007, p. 205).

As principais alterações realizadas no Setor Central foram: redução das zonas de comércio, alteração das dimensões das principais quadras e avenidas, além da Praça Cívica passar a ter um traçado radial. A Praça Cívica passou também a ser mais aberta e ganhou espelhos d'água e um monumento diferente do previsto. Corrêa Lima havia previsto um monumento do bandeirante para essa praça, mas no local foi inserido o monumento das três raças, representando os construtores da capital (DINIZ, 2007, p. 210-211).

A arquitetura presente nas casas segue o conceito do "Moderno", vindo com a construção da cidade, e as edificações no centro de Goiânia ganham estilos Art Déco, Eclético e Moderno (BARREIRA; DEUS, 2006, p. 79.)

[...] Goiânia, a nova capital do estado de Goiás, criada em 1933, com urbanismo e primeiros edifícios (palácio do governo, prefeitura e hotel) projetados por Attilio Corrêa Lima, tem imponentes monumentos Déco, como o teatro da cidade e a antiga estação ferroviária, além dos pioneiros palácios. (SEGAWA, 2002, p. 62).

O Setor Sul foi um bairro inicialmente zoneado para locar as habitações da cidade de Goiânia segundo o projeto de Corrêa Lima. O Setor Sul teve seu traçado definido em leque, seguindo a topografia do terreno (DINIZ, 2007, p. 129).

A zona residencial foi instalada em regiões próximas às áreas de matas, cerradão e veredas, proporcionando tranquilidade e conforto ambiental, além da facilidade aos bairros tanto "suburbanos" - Setor Sul e Oeste - como "urbanos" - Setor Central - pelas avenidas-parques (Alameda 115, das Rosas, dos Buritis, do Botafogo e Av. Oeste). (MONTEIRO, 1938, p. 68.) 
O Setor Sul, por sua vez, foi o primeiro bairro planejado fora do projeto original da cidade concebido pelos Irmãos Coimbra Bueno (Construtora Coimbra Bueno), sob a consultoria de Armando de Godoy. O bairro novo possui um conceito diferente: o conceito de cidade-jardim advindo de concepções urbanísticas da Europa e dos Estados Unidos.

Cidade-jardim, idealizada por Ebenezer Howard, era uma proposta de construção de pequenas cidades que uniriam o rural ao urbano, utilizando urbanização planejada. As cidades teriam expansão controlada através de cinturões-verdes que as limitariam e nelas seriam desenvolvidas atividades sociais, econômicas e culturais. Era considerada por muitos autores como um pensamento utópico, mas teve influência não só em discussões futuras, como também em planejamento de novos bairros e cidades (SILVA, 2014, p. 32-36).

\begin{abstract}
Godoy fez algumas alterações no projeto de Attilio, como a "redefinição de bosques e jardins, que passaram a formar um anel verde em torno da cidade. Os novos bairros deveriam localizar-se em regiões posteriores ao anel, formando cidades-satélites" (BERNARDES, 2000). O engenheiro também fez modificações no zoneamento proposto por Attilio Corrêa Lima. No Setor Sul (bairro residencial) incluiu o sistema cul-de-sac de ruas internas baseado nas cidades-jardins europeias e americanas e no qual as fachadas das casas se voltam para as praças internas, saindo os fundos para vielas onde é recolhido o lixo. Com o desenvolvimento da cidade, esse sistema inverteuse, contrariando o planejamento de Godoy. (MARINHO, 2006, p. 122)
\end{abstract}

Projetado entre os anos de 1935 a 1937, o Setor Sul tem como referência o projeto da cidade de Radburn, nos EUA, de Clarence Stein, que por sua vez fora inspirada nas ideias de Howard Ebenezer (VIEIRA, 2012, p. 63)

[...] Um plano inspirado em Radburn, uma cidade americana. [...] Na Zona Sul é que surgirá a mais moderna solução urbanística do momento atual. Será aqui realizada [...] a solução mais técnica para cidades modernas [...]. Tratase de uma concepção inteiramente nova no Brasil: adoção do sistema "culde-sac", grupos residenciais em forma semi-circular, em meio a um extenso parque, gramado e com arborização adequada, que mereceu estudos especiais. (ÁLVARES, 1942, p. 146)

O bairro passa de um traçado retilíneo, com formas regulares de Attilio, para um traçado orgânico, referência do modelo norte-americano. O projeto estimulava a convivência harmônica entre os moradores e tráfego de veículos desacelerado contando com o fluxo de veículos separado do fluxo de pedestres.

No projeto original, os lotes teriam duas entradas: uma para o cul-de-sac, concebido 
como ruas de serviço, e outra para área verde, acesso principal. Foram criados 28 espaços verdes públicos e os lotes variavam de $346 \mathrm{~m}^{2}$ a $894 \mathrm{~m}^{2}$ com dimensões irregulares devido ao traçado (MOTA, 2016, p. 4)

No projeto do bairro também foi proposta a criação de áreas verdes internas e equipamentos como escolas, hospitais, jardins, áreas de lazer e parques infantis, como forma de promoção de boa convivência entre os moradores e maior qualidade de vida. O projeto se inspirou nos modelos europeus e norte-americanos, sem pensar na sua aplicabilidade em uma cidade recém-criada no meio do sertão brasileiro, bem diferente de onde havia sido aplicado, resultando, então, em apropriação diferente do projeto original, com as fachadas se tornando os fundos das casas e vice-versa.

\section{Goiânia e sua inconstante mudança}

Explanando sobre os projetos de ambos os bairros da capital, Marinho (2006, p. 123) divide a produção do espaço urbano de Goiânia em anos:

$$
\begin{aligned}
& \text { 1a. - } 1933 \text { a } 1950 \text { - criação do lugar; } \\
& \text { 2a. - } 1950 \text { a } 1964 \text { - ampliação do espaço; } \\
& \text { 3a. - } 1964 \text { a } 1975 \text { - a concentração dos lugares; } \\
& \text { 4a . - a partir de } 1975 \text { - expansão urbana. }
\end{aligned}
$$

A definição da produção do espaço é basicamente uma linha do tempo mostrando o que ocorreu nos anos de 1933 a 1975 na capital. Goiânia passa, nesse tempo, por um crescimento tanto de seu território quanto populacional.

\footnotetext{
Por possuir características atrativas, Goiânia recebeu forte fluxo de imigrantes, sobretudo advindos dos estados do Maranhão, Pará, Piauí, Bahia e Minas Gerais, o que, acrescido ao processo migratório intraestadual, ao êxodo rural e ao crescimento vegetativo, ocasionou um intenso crescimento demográfico, principalmente entre as décadas de 1950 e 1980. (NASCIMENTO; OLIVEIRA, 2015, p. 144).
}

Quanto à primeira fase de produção de espaço de Marinho (2006): 
[...] a primeira fase de expansão e ocupação do território corresponde à data de fundação de Goiânia, em 1933, e vai até 1950. Nessa época ocorreu a criação do lugar e foi quando o estado usou a construção da cidade como uma plataforma política de progresso, desenvolvimento e estratégia de afirmação do poder. (BELLORIO, 2013, p. 39).

O período de ampliação do espaço (1950-1964) se deu a partir dos proprietários de terras parcelando suas glebas de forma extensiva. Essa fase foi um dos símbolos do progresso de Goiânia (MORAES, 1991, p. 37).

\begin{abstract}
O censo do IBGE aponta que a população da cidade de Goiânia passa de 26.065 em 1940 para 52.201 em 1950 e para 151.01 na década de 1960. Isso praticamente obriga o estado e a prefeitura a fazer um planejamento a partir dos anos 1960, na tentativa de reverter o caos urbano que a cidade vivenciava. (BELLORIO, 2013, p. 54).
\end{abstract}

Com esse relativo aumento populacional na cidade, o Setor Central já se encontrava consolidado, pois foi o primeiro bairro a ser construíd o e o Setor Sul começava a ser ocupado. Na década de 60, o Setor Sul passa a ter urbanização, considerada lenta e tardia, e gera crescimento populacional no local (MOTA, 2006, p. 7)

Mas foi somente na década de 1970 que se inicia o processo de consolidação do Setor Sul até a Praça do Cruzeiro. Os edifícios em altura começaram a ser liberados por intermédio do Plano de Desenvolvimento Integrado (PDIG) somente a partir de 1970 nesses lugares como solução ao alto número de habitantes. Os edifícios em altura começaram a ser implantados no Setor Central a partir da década de 1970. Já no Setor Sul, na década de 1980, foi liberada a construção de edifícios nas vias estruturadoras $84,85,86,87$ e 88 .

As Figuras 1 e 2 apontam transformações no Setor Central de 1968 a 2019. O bairro está consolidado em 1968 (Figura 1) e na Figura 2 há edifícios em altura e também a Praça Cívica modificada, revitalizada em 2016, sem estacionamento em seu interior. 
Figura 01 - Setor Central, Praça Cívica em 1968, Goiânia-GO

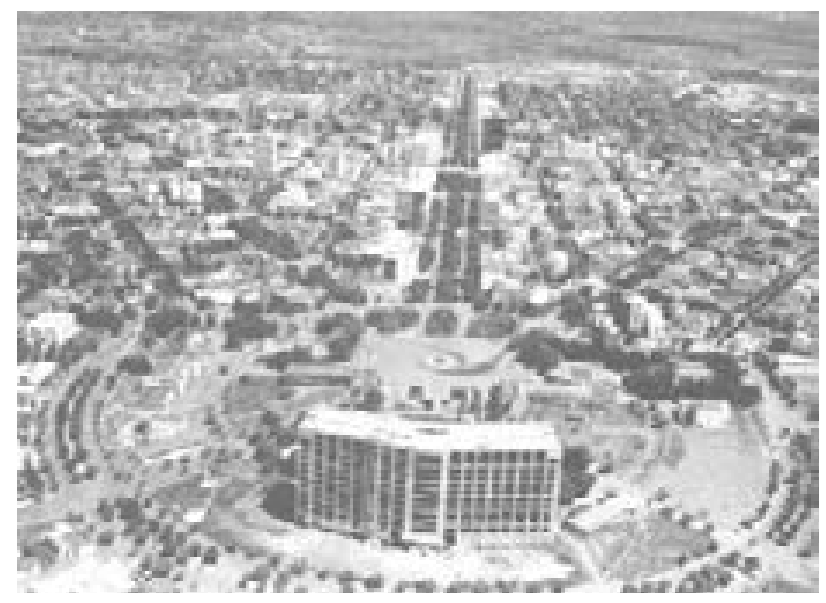

Fonte: Oliveira (2009).

Figura 02 - Setor Central, Praça Cívica em 2019, Goiânia-GO

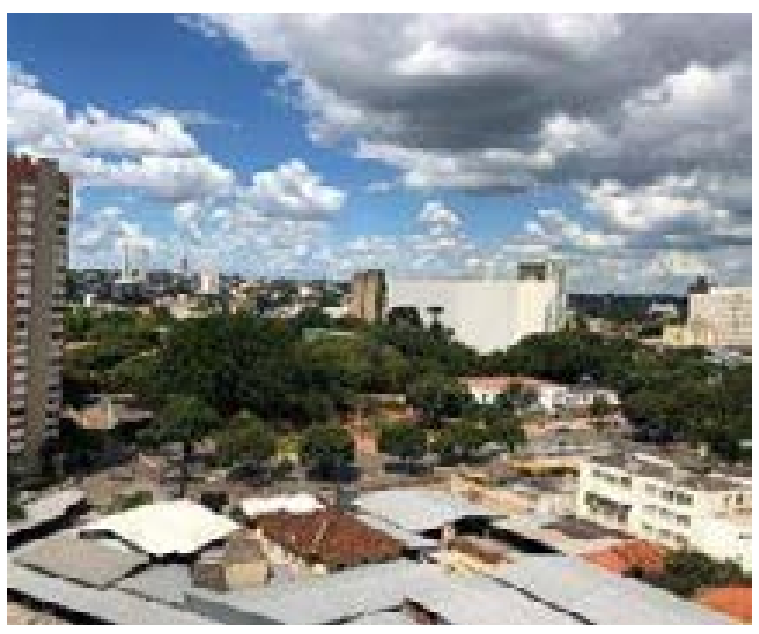

FONTE: Os autores (2019).

Quanto ao Setor Sul, este era pouco urbanizado em 1962 (Figura 3). Diferentemente, em 2019, estava totalmente consolidado com equipamentos como escolas, edifícios, comércios e residências (Figura 4). 
Figura 03 - Setor Sul em 1962, Goiânia-GO

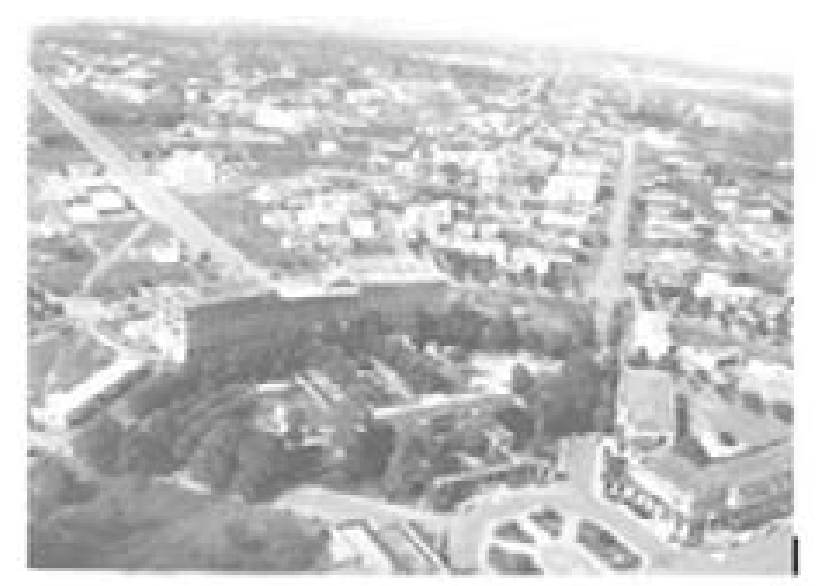

Fonte: Oliveira (2009).

Figura 03 - Setor Sul em 2019, Goiânia-GO

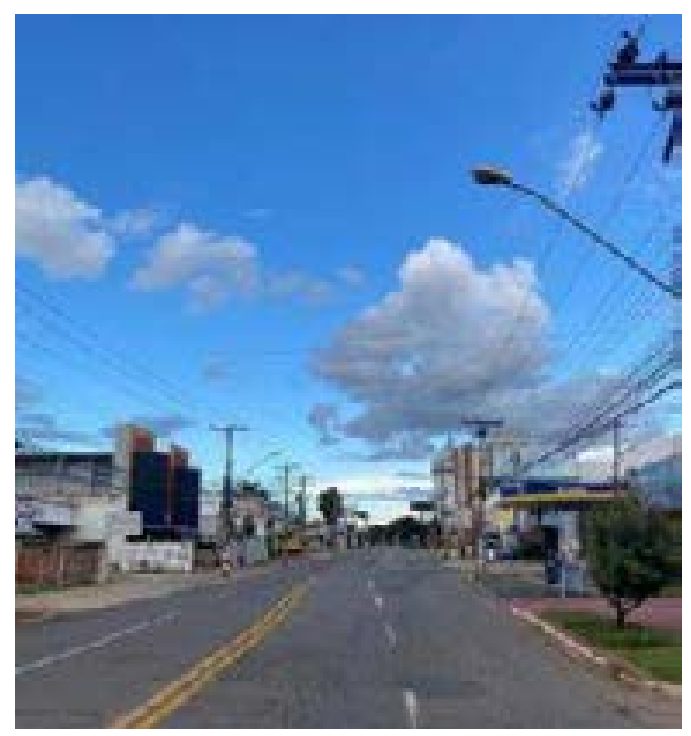

Fonte: Os autores (2019).

Quanto à paisagem urbana dos dois bairros, estes são consolidados e apresentam infraestrutura. O Setor Central é marcado pela presença de muitos comércios e serviços, principalmente ao longo de suas vias principais. Há também duas feiras: a Feira Hippie e a Feira do Mercado Aberto que fica fixa na Avenida Paranaíba. Além disso, existem residências, incluindo edifícios. A maior parte do bairro conta com edificações baixas e inspirados no estilo Art Déco. 
Como foi citado, o bairro foi pensado com potencial comercial. Ele ainda apresenta essa forte característica, contando com estabelecimentos que comercializam diversos tipos de produtos. Uma pesquisa elaborada pelo Sebrae (Tabela 01) aponta o número de empresas no Setor Central, contabilizando um total de 7.448, sendo 6.874 MPEs e 574 MGEs.

Tabela 01 - Quantitativo de Empresas presentes do Setor Central de Goiânia no ano de 2019

\begin{tabular}{|c|c|}
\hline \multicolumn{2}{|l|}{ Centro } \\
\hline Porte & Quantidade \\
\hline Médias / grandes & 574 \\
\hline Empresas de pequeno porte & 1062 \\
\hline Micro empresas & 4627 \\
\hline Microempreendedores Individuais & 1185 \\
\hline Sem porte definido & 585 \\
\hline Total de empresas & 8033 \\
\hline
\end{tabular}

\begin{tabular}{|l|c|}
\hline \multicolumn{2}{|c|}{ Centro } \\
\hline Setor econômico & Quantidade \\
\hline Agropecuária & 91 \\
\hline Comércio & 3325 \\
\hline Construção civil & 153 \\
\hline Indústria & 405 \\
\hline Serviços & 4019 \\
\hline Outros & 40 \\
\hline Total empresas & $\mathbf{8 0 3 3}$ \\
\hline
\end{tabular}

Fonte: Sebrae (2019).

O Setor Sul, planejado para uso residencial, conta também com parcela de uso comercial e de serviços. Possui 2.459 empresas, sendo 2.263 MPEs e 196 MGEs (Tabela 2).

Tabela 02 - Quantitativo de Empresas presentes do Setor Sul de Goiânia no ano de 2019

\begin{tabular}{|c|c|c|c|}
\hline \multicolumn{2}{|l|}{ Centro } & \multicolumn{2}{|c|}{ Centro } \\
\hline Porte & Quantidade & Setor econômico & Quantidade \\
\hline Médias / grandes & 196 & Agropecuária & 16 \\
\hline Empresas de pequeno porte & 501 & Comércio & 731 \\
\hline Micro empresas & 1664 & Construção civil & 158 \\
\hline Microempreendedores Individuais & 98 & Indústria & 213 \\
\hline Sem porte definido & 654 & Serviços & 1984 \\
\hline \multirow[t]{2}{*}{ Total de empresas } & \multirow[t]{2}{*}{3113} & Outros & 11 \\
\hline & & Total empresas & 3113 \\
\hline
\end{tabular}

Fonte: Sebrae (2019).

Assim como Attilio havia planejado, o Setor Central ainda concentra parte do Poder Administrativo. Nesse setor encontra-se o Palácio das Esmeraldas, sede do Governo do estado de Goiás e residência oficial do Governador; a Secretaria da Cultura do estado de Goiás; o Palácio Pedro Ludovico Teixeira, entre outros. 
O Setor Central conta com 19 unidades de saúde privada, mas apenas 04 dessas atendem pelo SUS (Sistema Único de Saúde), sendo a Clínica Santa Isabel, Hospital São Lucas, Hospital Otorrino de Goiânia e Centro de Odontologia Sebastião Alves Ribeiro. O bairro não possui nenhuma unidade de atendimento das redes de saúde pública municipal e estadual. Há apenas 01 unidade de saúde pública estadual de distribuição de medicamentos de alto custo.

O Setor Sul conta com 02 hospitais municipais, Centro de Atenção Psicossocial (CAPS) - AD / Casa e Centro de Atenção Psicossocial Infanto-juvenil (CAPS) Água Viva e 16 equipamentos de saúde privados, sendo que 04 dessas unidades atendem pelo SUS (Sistema Único de Saúde). Esses 04 são Hospital da Criança, Hospital Clínica do Esporte, Hospital Lio e Maternidade Modelo. É de significativa importância a presença de unidades de saúde nesses locais por prestarem assistência médica tanto preventiva quanto curativa à população. Ambos os setores são de fácil localização e acesso, o que facilita o atendimento dos pacientes.

O Setor Central conta com 07 colégios de ensino da rede pública, tanto municipal quanto estadual. Com relação às Instituições de Ensino Superior o Setor Central possui 04 Instituição de Ensino Superior (IES), sendo 01 pública e 03 privadas (Figura 5).

Figura 05 - Instituições de Ensino do Setor Central de Goiânia, 2019

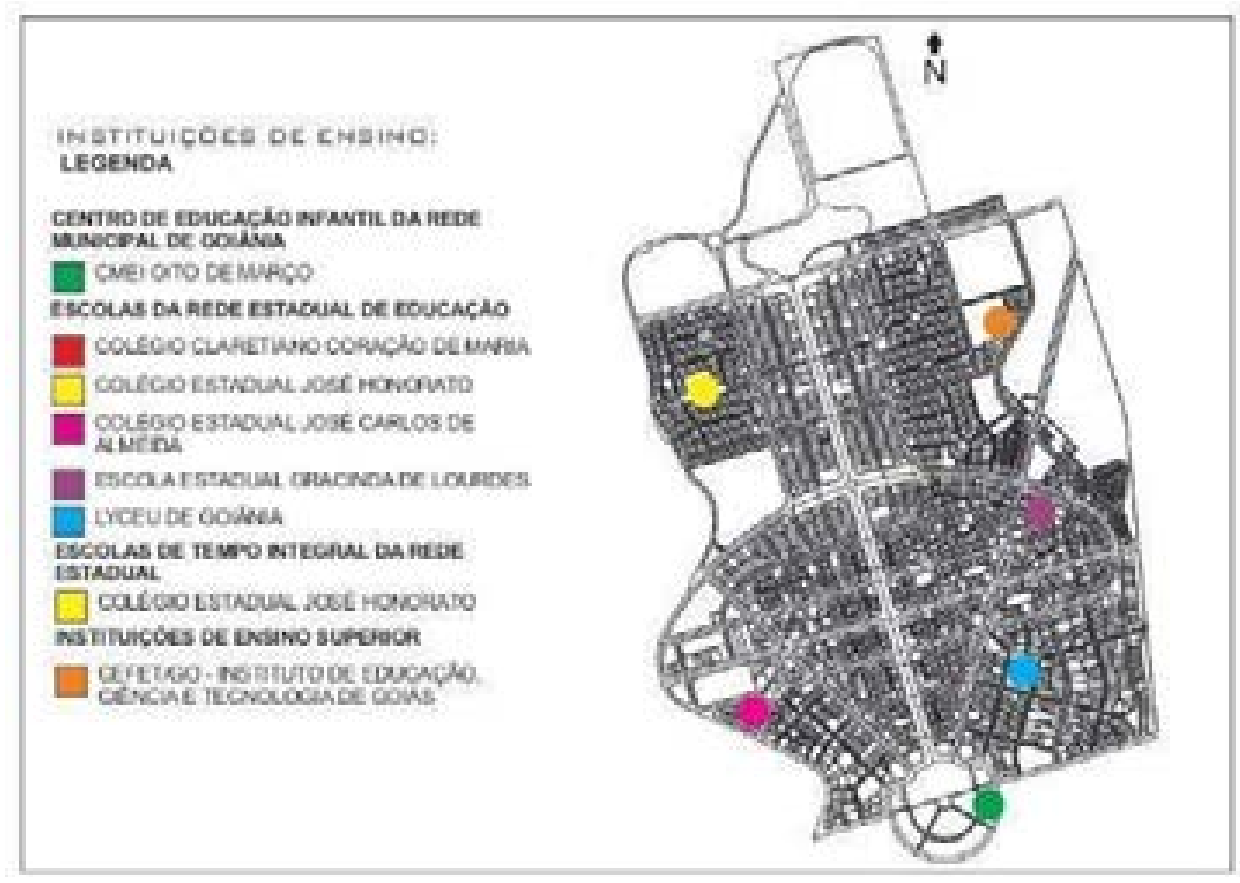

Fonte: Os autores (2019). 
Já o Setor Sul possui apenas 01 escola da rede pública municipal e nenhuma escola da rede pública estadual. Conta com 08 escolas privadas e 01 Instituição de Ensino Superior privada (Figura 6).

Figura 05 - Instituições de Ensino do Setor Sul de Goiânia, 2019

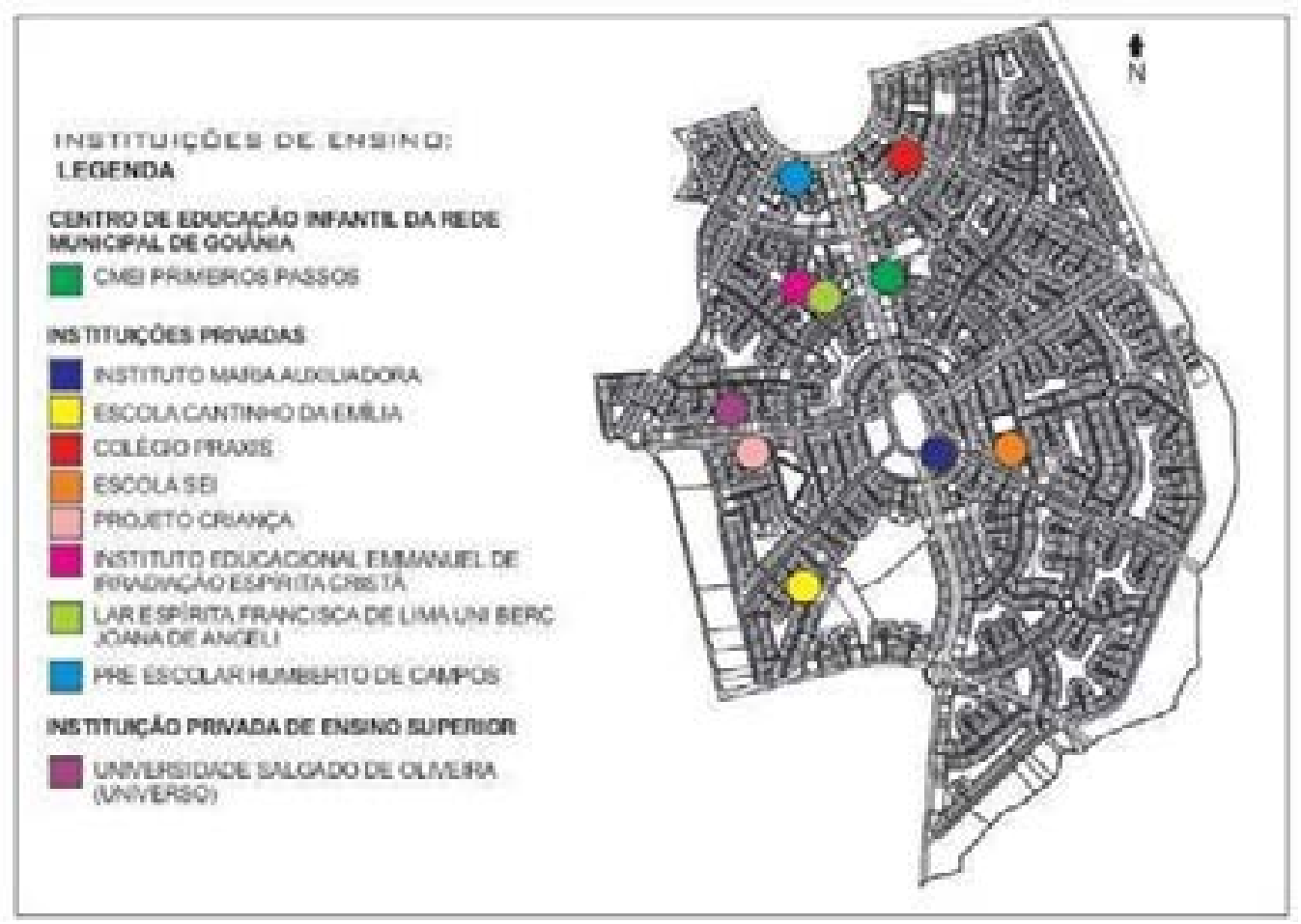

Fonte: Os autores (2019).

Esses números apontam para uma das características mais marcantes desses dois bairros: o fato de terem se tornado referência em serviços de educação e saúde da capital. Pessoas de toda a região metropolitana de Goiânia e também de outras partes do estado se direcionam para esses bairros para realizar tratamentos médicos e estudar. Certamente, essa é uma tendência de ocupação urbana dos Setores Central e Sul que vem se consolidando ao longo dos anos e que deve seguir acontecendo nos anos vindouros.

Nos serviços de segurança pública, o Setor Central possui uma delegacia de polícia civil e um departamento da polícia militar. Já o Setor Sul possui uma delegacia de polícia civil e nenhum departamento da polícia militar.

Nos serviços de atendimento ao público, o Setor Central e o Setor Sul não contam com nenhuma unidade da rede de Atende Fácil da Prefeitura de Goiânia. Já com relação ao 
atendimento da rede de Vapt-Vupt do governo de Goiás, o Setor Central possui 02 unidades, mas o Setor Sul não tem nenhuma.

Quanto à questão dos pontos de referência (Figura 7), além da Praça Cívica, o Setor Central ainda conta com vários outros, sejam eles edifícios importantes, locais de lazer, praças, monumentos ou mercados. Devido a sua construção e sua história, estes representam as características essenciais do bairro.

Figura 07 - Pontos de Referência do Setor Central de Goiânia, 2019

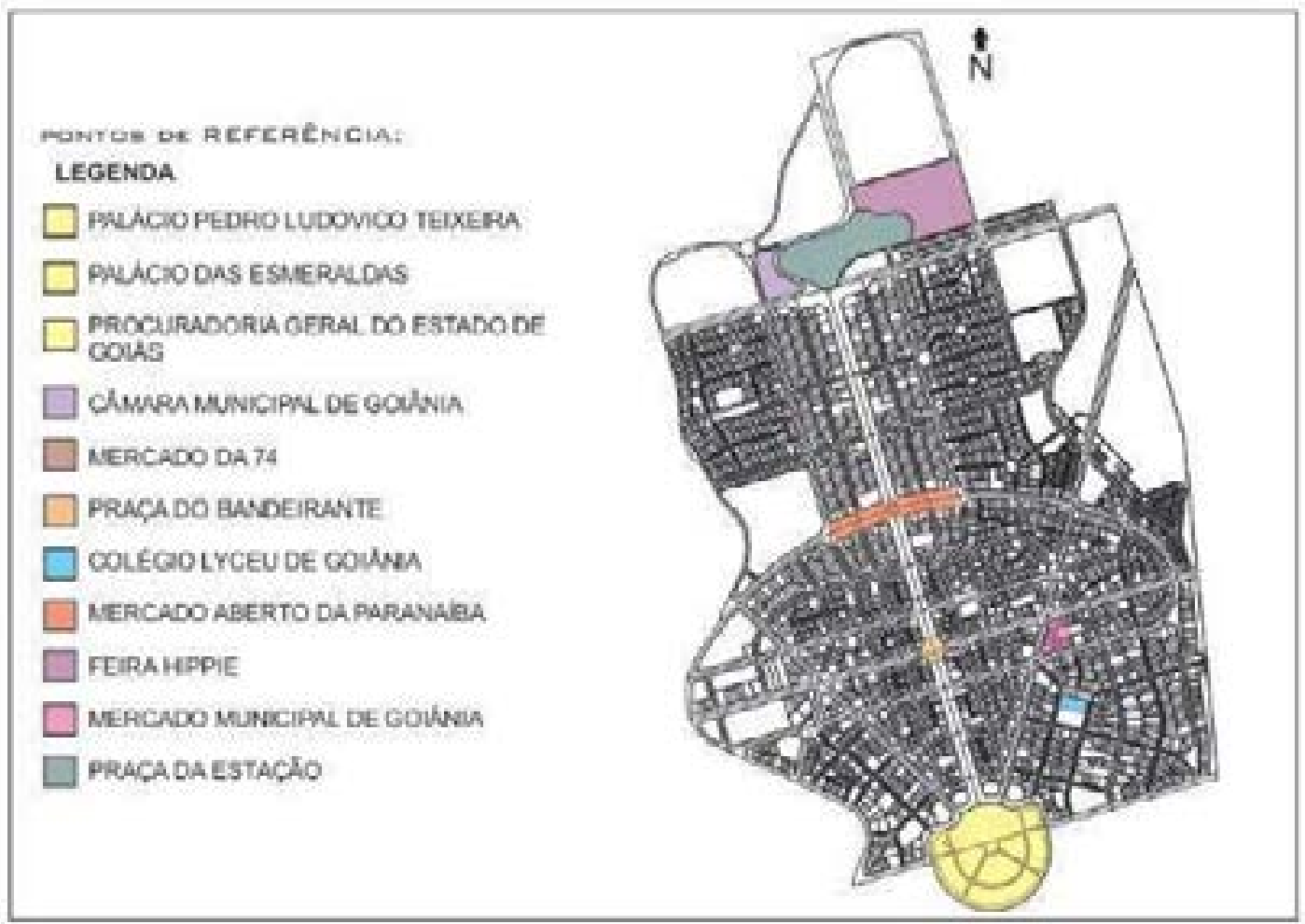

Fonte: Os autores (2019).

Quando Attilio idealizou o Setor Central, o arquiteto pensou no Centro Cívico como algo moderno e monumental, que pudesse ser visto de outros pontos de Goiânia. Apesar de a Praça Cívica não ser visível de outros locais da cidade pela quantidade de edifícios presentes, ela ainda se faz um marco, o principal ponto de referência da cidade, concentrando edifícios administrativos importantes para toda a população, além também de ser o "radiador" das principais avenidas, distribuindo o fluxo de veículos.

O Setor Sul, apesar de ter ganhado um novo traçado, diferente do original de Attilio, 
é um bairro bem característico da capital. Apresenta pontos que se tornaram referência, principalmente suas praças. Na Figura 08 pode ser vista a localização desses pontos de referência.

Figura 08 - Pontos de Referência do Setor Sul de Goiânia, 2019

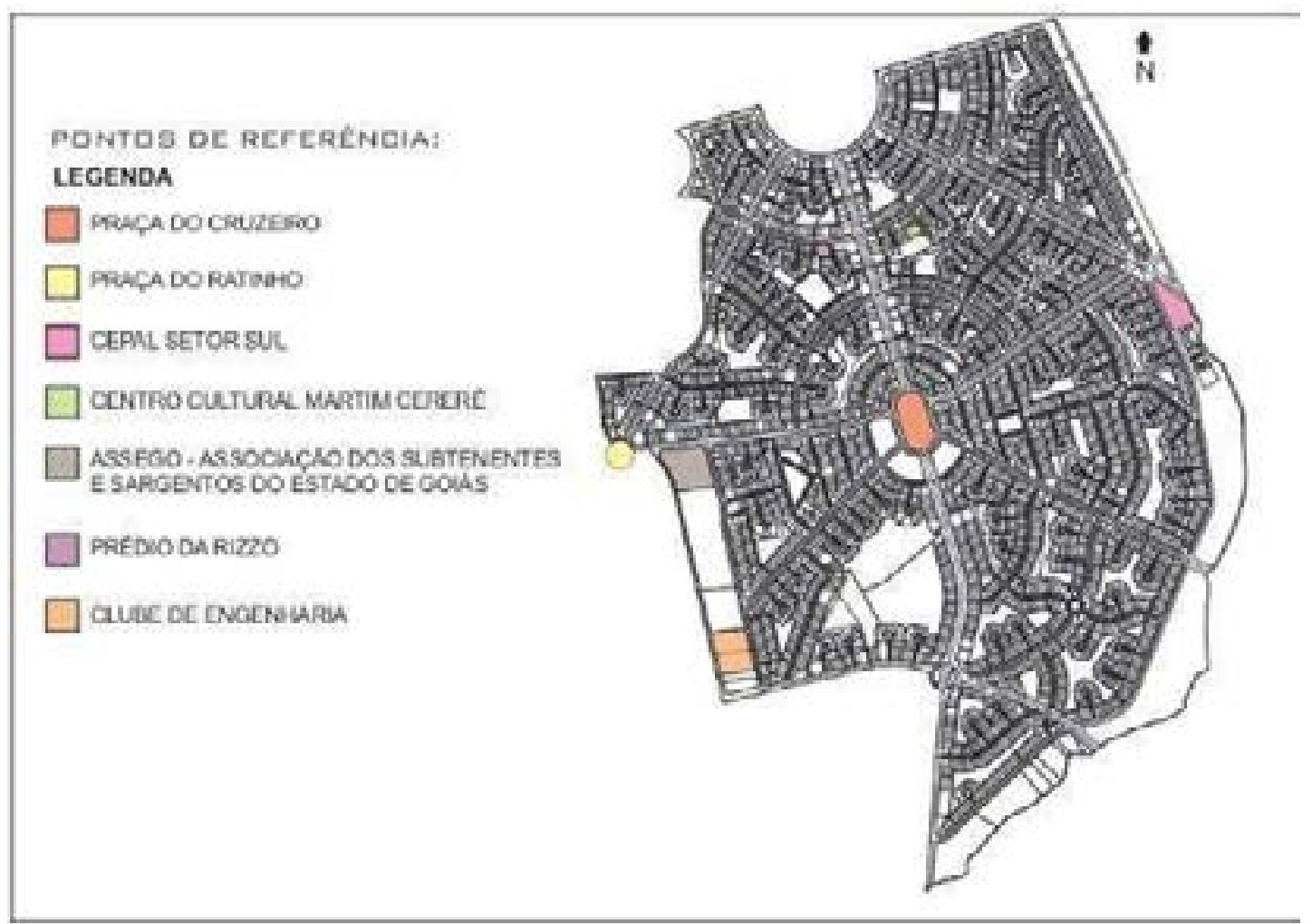

Fonte: Os autores (2019).

O Setor Central foi o primeiro bairro consolidado de Goiânia, apresentando maior número de edifícios históricos e importantes da capital. Estes contam a história da fundação da cidade e daqueles que trabalharam em sua construção. Portanto, foram tombados pelo Instituto de Patrimônio Histórico e Artístico Nacional (IPHAN). A Tabela 3 mostra quais são os monumentos e espaços públicos tombados no Setor. O próprio traçado da Praça Cívica foi tombado em 2002 e abrange 22 bens. 
Tabela 03 - Monumentos e Espaços Públicos tombados do Setor Central de Goiânia

\begin{tabular}{|l|l|}
\hline \multicolumn{2}{|c|}{ Itens Tombados no Setor Central } \\
\hline Palácio das Esmeraldas & Chefatura de Polícia \\
\hline Colégio Estadual Lyceu de Goiânia & Obeliscos \\
\hline Coreto & Fontes Luminosas \\
\hline Teatro Goiânia & Antiga Escola Técnica de Goiânia (IFG) \\
\hline $\begin{array}{l}\text { Antigo Fórum e Tribunal de Justiça (Procuradoria } \\
\text { Geral do Estado) }\end{array}$ & Tribunal Regional Eleitoral \\
\hline Antiga Estação Ferroviária & $\begin{array}{l}\text { Departamento Estadual de Informação (Museu } \\
\text { Zoroastro Artiaga) }\end{array}$ \\
\hline Torre do Relógio & Casa de Pedro Ludovico Teixeira \\
\hline Grande Hotel & Delegacia Fiscal \\
\hline Secretaria Geral (Centro Cultural Marieta Telles) & \\
\hline
\end{tabular}

Fonte: IPHAN (2002).

No Setor Sul não há itens tombados pelo Instituto de Patrimônio Histórico e Artístico Nacional (IPHAN); há somente bens tombados no âmbito municipal -Conselho Municipal de Preservação do Patrimônio Histórico, Cultural e Ambiental (CMPPHCA). São eles: a Praça Comendador Germano Roriz e o Centro Cultural Martim Cererê.

Tabela 04 - Itens tombados do Setor Sul de Goiânia

\begin{tabular}{|c|}
\hline Itens Tombados Setor Sul \\
\hline Centro Cultural Martim Cererê \\
\hline Praça Comendador Germano Roriz \\
\hline
\end{tabular}

Fonte: CMPPHCA (2019).

Os Setores Central e Sul, por estarem localizados dentro no núcleo original da cidade, recebem a convergência e a distribuição de um extenso fluxo das linhas de transporte coletivo da cidade de Goiânia, bem como recebem enorme quantidade de automóveis particulares que cortam a cidade em seus trajetos casa-trabalho-lazer.

Ainda a respeito da mobilidade, há três aspectos que são positivos presentes nos Setores Central e Sul. O primeiro é o desenho arquitetônico viário original, que previa desde o início o traçado com largas Avenidas como a Goiás, a Araguaia, a Tocantins e a Paranaíba no Setor Central, e as Avenidas 83, 84, 85, 87, 90 no Setor Sul, sendo isso um facilitador do 
fluxo de veículos.

O segundo aspecto positivo é a existência de largos eixos viários da capital, que cruzam os Setores Central e Sul da cidade: o eixo leste-oeste, composto da Avenida Anhanguera; o eixo norte-sul, composto das Avenidas Goiás, 84 e, mais adiante, 90; e o eixo composto pela Marginal Botafogo.

O terceiro é que eles possuem o amplo acesso aos serviços de transporte coletivo da cidade, já que a maior parte das linhas alimentadoras da capital possuem conexão com os Setores Central e Sul. Segundo a Rede Metropolitana de Transportes Coletivos (RMTC), o Setor Central recebe 49 linhas de ônibus que levam a todos os eixos da cidade. Já o Setor Sul, pela proximidade com o centro, recebe 37 linhas de ônibus. Além das linhas tradicionais de ônibus, ambos os setores ainda recebem o Citybus 2.0, o novo serviço de transporte coletivo por aplicativo de celular iniciado na cidade de Goiânia em 2019.

Com relação ao modal de mobilidade urbana cicloviário, há pequeno trecho que vai da Praça Cívica ao Bosque dos Buritis. Nesse caso, há possibilidade de melhoria para os dois bairros com a implantação de mais ciclovias e ciclofaixas.

Quanto à infraestrutura, tanto a do Setor Central quanto a do Setor Sul, todas as suas vias são asfaltadas e iluminadas, todos os imóveis possuem os serviços de energia elétrica, de saneamento básico com redes de água tratada e esgotamento sanitário e acesso às redes de telecomunicações fixa e móvel.

Com relação à densidade populacional dos dois setores, constata-se que ambos estão estagnados. Entre o período de 2000 a 2010, segundo o Censo do IBGE, a população do Setor Central ficou praticamente estável, partindo de uma população de 23.233 habitantes, para 23.317 habitantes. Nesse mesmo período, a população do Setor Sul decresceu 14\%, saindo inicialmente de 13.530 habitantes para 11.677 habitantes.

A população do Setor Sul decresceu, o que pode ser explicado pelo alto número de empresas, principalmente no setor de serviços. Essa perda de população constata, também, que há maior procura pela ocupação do bairro com comércios e o setor de prestação de serviços.

Segundo o Plano Diretor de Goiânia de 2007, ambos os bairros não fazem parte do processo de adensamento da cidade. $O$ crescimento da cidade tem acontecido tanto pela abertura de novos bairros e loteamentos quanto pela verticalização, com a construção de edifícios residenciais e comerciais em outras áreas adensáveis. No entanto, o Setor Central 
manteve a sua população. Isso pode significar que as áreas mais residenciais desse bairro continuam atraindo moradores e que o apetite expansionista dos segmentos de comércio e serviços ainda não atingiu a parte dos imóveis mais residenciais.

Apesar de ambos os setores não apresentarem alta demanda populacional nos últimos anos, a cidade de Goiânia foi uma das capitais brasileiras com maior crescimento na década de 2010, apresentando taxa média de crescimento anual no período de 2000 a 2010 de 1,77, segundo o Censo 2010 (BERNARDES; BORGES; TEIXEIRA, 2017, p. 10).

\section{Conclusão}

A partir de todo o apanhado histórico da criação da capital do estado de Goiás, foi possível entender a concepção urbanística de Attilio Corrêa Lima e Pedro Ludovico Teixeira. O projeto inovador de uma capital conciliava com o que acontecia no país: a Revolução de 1930. Esse conceito moderno é visível principalmente quando se analisa o traçado e a criação do centro cívico.

Depois de fundamentado o projeto, foi visto que até mesmo logo depois de finalizado, o traçado da cidade já havia se alterado. Não se sabe ao certo se a especulação imobiliária, a pressão política ou as péssimas condições de trabalho levaram à saída de Attilio Corrêa Lima; o que se sabe é que houve mudanças consideráveis, principalmente no bairro de estudo, o Setor Sul.

O Setor Central, apesar de passar por modificações de projeto com a entrada dos Irmãos Coimbra Bueno, ainda possui fortes raízes entrelaçadas com o projeto original de Goiânia. As ruas, apesar de não manterem as largas metragens propostas anteriormente, são vias arteriais e largas, além de serem as principais conectoras do restante da cidade.

A Praça Cívica, apesar de alterada sua forma e o monumento que ali seria inserido, apresentava a função de um centro administrativo e continua como a referência de um local que concentra equipamentos públicos. Ali se concentram os principais edifícios referentes ao estado de Goiás, incluindo os palácios previstos no antigo projeto. A Praça Cívica continua sendo o principal ponto de referência da cidade, algo que foi planejado por Attilio Corrêa Lima.

Quanto às zonas propostas para o Setor Central no projeto de Corrêa Lima, o uso 
de solo do bairro ainda possui características da sua concepção urbanística. O Setor Central apresenta vários equipamentos públicos, incluindo edifícios, como o Centro Administrativo e a Procuradoria Geral do estado de Goiás, possuindo comércios principalmente ao longo das vias arteriais e também as feiras. Mas há também a presença de residências e equipamentos públicos, como escolas. O bairro também conta com vários itens tombados pelo Instituto de Patrimônio Histórico Nacional.

Já o Setor Sul recebeu um novo projeto quando os Irmãos Coimbra o assumem junto com o Engenheiro Armando de Godoy. Este acaba sendo descaracterizado posteriormente pelos moradores do local. O conceito dos jardins como entrada das residências não foi utilizado e se inverteu a concepção prevista pelos idealizadores.

Ao longo dos anos, esses espaços verdes ficaram sem função alguma e sem amparo, tanto pela sociedade quanto pelos governantes. O novo projeto previsto para o Setor Sul não foi pensado para a população que ali iria residir, portanto, não teve aceitação e nem entendimento de como iria funcionar o sistema cul de sac e os espaços verdes. Vista o quão se degradaram essas áreas, houve empenho dos moradores e ativistas e, assim, foram criados projetos que visam ao seu uso.

Apesar do projeto original ser descaracterizado, o Setor Sul havia sido previsto como zona residencial e assim permaneceu, mas atualmente conta com uma considerável parcela do setor de comércio e serviços. Houve queda no número de habitantes, que pode ser explicada por essa expansão da zona de comércio e serviços, algo que foi alterando a configuração do bairro.

Conclui-se que os dois bairros possuem vitalidade da atividade econômica, especialmente relacionada aos setores de comércio e serviços: o Setor Central por ter sido projetado desde o início com a perspectiva de incluí-la na sua dinâmica; já o Setor Sul foi projetado para ser apenas residencial, mas com o tempo foi ampliando a sua atividade econômica, principalmente na área de serviços.

O que foi perceptível com a pesquisa é que o Setor Sul foi ganhando esse espaço comercial e que futuramente pode se tornar um setor com uma parcela maior de comércio e serviços que residencial, como é sua atual configuração. O Setor Central é um local com um cunho histórico muito importante para a construção da capital de Goiás, logo, no futuro, há uma possibilidade de que o patrimônio histórico e cultural desse setor possa ser explorado economicamente. 
Apesar de passarem por modificações em suas concepções urbanísticas, esses setores são imprescindíveis para a economia e para a história da cidade de Goiânia, e mesmo sendo bairros antigos, ainda são valorizados e ostentam pontos de referência importantes na cidade.

\section{Agradecimentos}

Os autores agradecem à Coordenação de Aperfeiçoamento de Pessoal de Nível Superior (CAPES), a qual possibilitou o desenvolvimento deste trabalho através da concessão de bolsa de pesquisa.

\section{Referências}

BARREIRA, Aluízio Antunes; DEUS, João Batista de. Goiânia - da utopia à construção do lugar. Goiânia: Boletim Goiano de Geografia, v. 26 n. 1, jan./jun. 2006.

BELLORIO, Grazielli Bruno. Adensamento e verticalização em Goiânia nos Planos Diretores 1968-2000. Goiânia: Pontifícia Universidade Católica de Goiás, 2013.

BERNARDES, Genilda D'arc; BORGES, Leandro Bernardes; TEIXEIRA, Ricardo Antônio Gonçalves. Repensando Goiânia: da construção aos dias atuais. Baru, Goiânia, v. 3, n. 1 jan./jul. 2017.

CHAUL, Nars Fayad. Goiânia: a capital do Sertão. Revista UFG, Goiânia, n. 6, jun. 2009.

DEL RIO, Vicente; SIMBIEDA, William. Desenho urbano contemporâneo no Brasil. Rio de Janeiro: LTC, 2013.

DINIZ, Anamaria. Goiânia de Attilio Corrêa Lima (1932-1935) - Ideal estético e realidade política. Brasília: Universidade de Brasília, 2007.

GERHARDT, Tatiana Engel, SILVEIRA, Denise Tolfo. Métodos de pesquisa. Porto Alegre: UFRGS, 2009.

GOIÂNIA (Município). Prefeitura Municipal de Goiânia. Secretaria Municipal da Casa Civil Lei Complementar no 171, de 29 de maio de 2007.

INSTITUTO BRASILEIRO DE GEOGRAFIA E ESTATÍSTICA (IBGE). Pesquisa Nacional população por bairros de Goiânia no ano 2010. Goiânia: IBGE, 2010.

MARINHO, Clorisnete Borges. Região Sul de Goiânia: um lugar valorizado na metrópole. GEOUSP - Espaço e Tempo, São Paulo, n. 19, 2006.

MONTEIRO, Ofélia Sócrates do Nascimento. Como nasceu Goiânia. Revista dos Tribunais, São Paulo, 1938.

MORAIS, Lucia Maria. A segregação planejada: Goiânia, Brasília e Palmas. Goiânia: UCG, 2003. 
MORAES, Sérgio de. 0 empreendedor imobiliário e o Estado: o processo de expansão de Goiânia em direção sul 1975-1985. Brasília: Universidade de Brasília, 1991.

MOTA, J. C. O Setor Sul em Goiânia: o espaço público abandonado. Revista do.co.mo.mo, Rio de Janeiro, 2016.

NASCIMENTO, Diego Tarley Ferreira; OLIVEIRA, Ivanilton José de. Mapeamento do processo histórico de expansão urbana do município de Goiânia. Geographia, Niterói, n. 34, 2015.

NEVES, Priscila P. C. Identidade Setor Sul, Goiânia-GO: croquis urbanos e o reconhecimento dos jardins internos. Pixo - Revista de Arquitetura, Cidade e Contemporaneidade, Pelotas, v. 1, n. 2, 2017.

OLIVEIRA, Hélio de. Eu vi Goiânia crescer: décadas de 50 e 60. Goiânia: Hélio de Oliveira, 2009. v. 1.

VIEIRA, Patrick di Almeida. Attilio Corrêa Lima e o planejamento de Goiânia - Um marco moderno na conquista do sertão brasileiro. URBANA - Revista Eletrônica do Centro Interdisciplinar de Estudos Sobre a Cidade, Campinas, v. 4, n. 4, mar. 2011.

SEGAWA, Hugo. Arquiteturas no Brasil 1900-1990. 2. ed. São Paulo: Universidade de São Paulo, 2002.

SILVA, Alessandra Rosa da. A cidade-jardim de Ebenezer Howard: um estudo de sua influência para a circulação de ideias e modelos de urbanismo do século XX. Natal: Universidade Federal do Rio Grande do Norte, 2014.

SILVA, Genilder Gonçalves da; MELLO, Marcelo de Mello. A Revolução de 1930 e o discurso da ruptura: Goiânia e a Marcha para o Oeste. Cordis - Revoluções, cultura e política na América Latina, São Paulo, n. 11, jul./dez. 2013. 